\title{
DOBLETES ETIMOLÓGICOS EN ESPAÑOL - SU ORIGEN Y EVOLUCIÓN SEMÁNTICA. OBSERVACIONES PUNTUALES
}

\author{
Abstract \\ Spanish etymological doublets - their origin and semantic development. \\ Comments on selected items
}

The present paper is devoted to the analysis of five arbitrarily selected Spanish etymological doublets in terms of their origin, i.e. the appearance of their constitutional elements in the language: of the learned word (cultismo) and the popular word (palabra popular), and of the semantic changes that arise by comparing the meaning of the Latin etymon with the contemporary meaning of the lexemes. The aim of the paper is to confront the commonly accepted theories on the issue of doublets (the later dating of the learned term and its more abstract meaning) with concrete lexical material. The analysis, although limited by space, shows that learned words are not infrequently contemporary with the popular words, their meaning is not always more abstract, almost all the meanings of the Spanish lexemes are connected with the meaning of Latin words, and their repartition is ruled by a more general principle of the limited number of meanings of the borrowed words.

\section{Datos preliminares}

Si bien, como admite Clavería Nadal (1991: 21) "la gramática tradicional se ha entusiasmado con el hecho de que de uno mismo étimo latino aparezcan dos o más resultados romances, es decir, dos palabras distintas", el tema de los dobletes, por más fascinante que parezca, no tiene una bibliografía extensa. Las únicas dos obras publicadas, plenamente dedicadas al estudio de los dobletes etimológicos en español, son: Estudio histórico-semántico de los dobletes múltiples en español moderno de Belén Gutiérrez (1989) y, redactado en ruso, Diccionario de dobletes etimológicos en la lengua española de I. Korolenko (1969). 
Ya el hecho de explicar la existencia de los dobletes mediante el "doble desarrollo" provoca discusiones: ¿realmente se puede hablar de un resultado doble si uno de los integrantes ha sido prestado después? (v. Saussure 1991: 183 y passim). No menos problemáticas resultan la delimitación y la descripción de estas parejas.

Teóricamente un doblete etimológico está constituido por una palabra popular y una voz culta, donde "tradicionalmente se consideran cultismos los vocablos latinos o griegos a través del latín, que, a causa de haber entrado en nuestra lengua por vía culta: la lengua literaria de la exposición teológica, filosófica, jurídica, matemática, etc., se integraron en ella con casi plenitud de sus características fonéticas y semánticas originarias" (Gutiérrez 1989: 10) ${ }^{1}$ y palabras populares que son resultado de un desarrollo regular. Como se sabe, puede intervenir el término terciario, llamado semicultismo, que según algunos (v. Alvar y Mariner 1967: 6) es un vocablo "frenado en su evolución" y aparece cuando "la acción de la cultura no fue bastante poderosa para mantener la integridad formal de la palabra, pero sí frenar o desviar el proceso fonético iniciado en ella" Lapesa (1980: 109), según otros (v. Wright 1976) es un término indefinible.

En cuanto a la fecha de introducción de los cultismos y palabras populares, se suele admitir que mientras los primeros son "voces literarias de introducción tardía en el idioma, tomadas de los libros cuando e latín clásico era ya lengua muerta" (Pidal 1992: 9), los segundos constituyen la parte patrimonial del léxico.

Como uno de los principales factores diferenciadores, además de la fonética y la cronología en una pareja de dobletes, es su bifurcación semántica, cabe recordar que generalmente se suele admitir que el significado de la voz patrimonial es el más específico, concreto o restringido y el de la voz culta suele padecer la ampliación semántica o mantiene el significado más abstracto: "nótese que las voces populares suelen tener un sentido más concreto y material que las eruditas" (Lapesa 1980, Torrens Álvarez 2007, Gutiérrez 1989). La misma teoría aparece en las obras dedicadas al tema de los dobletes en otros idiomas, v. gr. italiano (Sălişteanu-Cristea 2000) o ruso (Kalinin 1971, Šanskij 1964).

\section{Metodología aplicada}

Para averiguar susodichas teorías, del repertorio de Korolenko (1969), por ser el que trata de los dobletes "prototípicos" (simples) al contrario de los "múltiples" en la obra de Gutiérrez (1989), hemos escogido al azar cinco parejas que no dejan lugar a dudas en cuanto a su carácter doble, presentadas en orden: palabra culta / palabra popular:

\footnotetext{
${ }^{1}$ Por ser prácticamente idénticas, no citamos otras definiciones tales como las de M. Pidal (1982: 9), R. Lapesa (1980: 109) o R. Penny (2001: 34).
} 
acre / agrio

cálido / caldo

foco/fuego

masticar / mascar

sólido / sueldo.

El procedimiento fue el siguiente: presentar su etimología, basándonos en el diccionario etimológico (DCECH) de Corominas y Pascual, detectar las fechas de la primera aparición en español al examinar el corpus histórico de la Real Academia Española ${ }^{2}$ y comparar los datos obtenidos con la primera documentación de J. Corominas, examinar detalladamente el significado del étimo latino (en base de los siguientes diccionarios: Thesaurus lingauae latinae, Totius latinitatis Lexicon, A Latin dictionary, Nuevo diccionario latino-español etimológico, Nuevo diccionario etimológico latín-español y de las voces derivadas, Glossarium mediae et infimae latinitatis) y compararlo con el desarrollo semántico de las formas integrantes de cada doblete. Tras este análisis se espera saber más sobre la aparición del vocablo en el idioma y trazar, al menos de una manera general, la creación y la repartición de los significados para luego compararlo con los datos y las teorías que conocemos comúnmente de las obras dedicadas al respeto.

\section{Estudio de dobletes}

Lista de abreviaciones aplicadas:

APal. $=$ Alfonso Palencia. Universal Vocabulario. 1490.

DCECH = Corominas J., Pascual J. El diccionario etimológico castellano e hispánico. [vol. I-IV]. Madrid 1980.

Glossarium $=$ Cange du D. Glossarium mediae et infimae latinitatis. Niort 1884.

Lewis \& Short = Lewis C.T., Short C. A Latin dictionary. [versión on-line].

Lexicon $=$ Forcellini A. Totius latinitatis Lexicon . Prati 1858.

Nebrija 1481= Nebrija de A. Introducciones latinae. 1481.

Nebrija 1495 = Nebrija de A. Vocabulario español-latino. 1495.

Raimundo = Raimundo de M. Nuevo diccionario latino-español etimológico. Madrid 2003. [ $1^{\text {a }}$ ed. 1897].

Segura = Segura Munguía S., Santiago. Nuevo diccionario etimológico latín-español y de las voces derivadas. Bilbao 2006.

Thesaurus $=$ Thesaurus linguae latinae. . Lipsiae 1900.

\footnotetext{
${ }^{2}$ REAL ACADEMIA ESPAÑOLA: Banco de datos (CORDE) [en línea]. Corpus diacrónico del español. http://www.rae.es
} 


\section{acre / agrio}

acre en DCECH (I/43) figura únicamente como préstamo del ingl. acre 'íd.' o sea medida de superficie. En cuanto a la otra acepción del vocablo, Corominas nos remite a agrio. Allí agrio según Corominas (DCECH I / 77) viene del ant. agro alterado por influjo de agriar, del LV acer, acra, acrum 'agudo, penetrante' y LC acer, acris, acre; $1^{\text {a }}$ doc. s. XVI, mientras que la forma agro está documentada en 1251. También agrega que la forma agro es normal hasta el s. XVII (1604) aunque Cuervo habla de los ss. XV-XVI, en los diccionarios de Nebrija y Alfonso Palencia aparece solo la forma agro.

Según el examen del corpus histórico de la RAE, la forma agro efectivamente está documentada a mediados del siglo XIII:

Si supiese el que mucho usa temor dulce, que se melezinaríe por comer agro (Bocados de oro 1250);

aparece en la obra de Nebrija:

Oxizacre de agro con açucar (Nebrija 1495), Acer acris. por agro (Nebrija 1481), agra cosa (Nebrija 1495),

aunque en el "Tesoro" de Covarrubias (1611) solo con la acepción de 'campo' o en la composición agrodulce (Covarrubias 2003: 488).

El año 1636 es la fecha de la última documentación de agro.

agrio aparece por primera vez en los textos del s. XV:

E como quiera quel camino para entrar a ella era muy agrio e trabajoso, (Valera 1487-1488);

(...) hazia muj grand duelo agrio \& maravilloso Historia de la linda melosita, (Anónimo 1489);

Del sabor agrio capitulo .xlviii (Burgos 1494).

acre está documentado por primera vez en el s. XVI:

(...) los ajos toman de la tierra para su nutrición lo acre y mordaz, las lechugas lo dulce (Huarte 1575-1588).

Gracias al examen del corpus, hemos podido complementar la fecha de la primera aparición de acre: 1575-1588 y antedatar la de agrio (1487-1488) frente al s. XVI según Corominas.

Examinemos, a continuación, el desarrollo semántico del vocablo acer.

En latín acer poseía un amplio abanico de significados:

Según Thesaurus (I / 356-365):

1. de rebus / de hominibus / de bestii / de sensibus / de rerum (sensus, affectus, agentia)

2. acutis, asperior, crudelis, durus, fortis, perseverans, vehemns, austerum, acerbum....

Según el Diccionario de Lewis \& Short acer, cris, cre se puede aplicar en los siguientes campos:

1. gral.: afilado (sharp, pointed, piercing and the like);

2. sentidos (vista, oído, olfato, sabor, sensación): agudo (sharp, dazzling, stinging, pungent, fine); 
3. estados internos del sistema humano (internal status of human system): violent, sharp, severe, gnawing;

4. cualidades intelectuales: subtle, acute, penetrating, shrewd;

5. cualidades morales: active, ardent, pager, brave, zeaolus.

"Agri modus" explica Cange (1884 I: 53), mientras Segura (2006: 10) lo traduce a:

'agudo, penetrante, cortante, afilado' y remite el vocablo a: aguijones, vinagre, chisporrotes de la llama, fuerza, hambre, alimentos, espíritu, ojos, ingenio, soldado, caudillo, amor. Asimismo Raimundo (2003: 11) propone como equi-

valentes españoles: 'vivo, sutil, penetrante, deslumbrante, fino' y admite que al referirse a la vista, estado de cuerpo significa "sensaciones percibidas por los sentidos y de las cosas que les afectan".

Ahora, si nos fijamos en los significados que propone actualmente la $\mathrm{RAE}^{3}$ obtenemos el siguiente reparto de significados:

acre

1. adj. Áspero y picante al gusto y al olfato, como el sabor y el olor del ajo, del fósforo, etc.

2. adj. Dicho del genio o de las palabras: Áspero y desabrido.

3. adj. Med. Dicho del calor febril: Acompañado de una sensación como de picor.

\section{agrio}

1. adj. Que actuando sobre el gusto o el olfato produce sensación de acidez.

2. adj. Que se ha agriado.

3. adj. Difícilmente accesible; pendiente o abrupto.

4. adj. Acre, áspero, desabrido. Genio agrio. Respuesta agria.

5. adj. Dicho de un castigo o de un sufrimiento: Difícilmente tolerable.

6. adj. Dicho de un metal: Frágil, quebradizo, no dúctil ni maleable.

7. adj. Pint. Dicho del colorido: Falto de armonía o consonancia o de la necesaria entonación.

8. m. Zumo ácido.

9. m. pl. Frutas agrias o agridulces, como el limón, la naranja y otras semejantes.

Es cierto que agrio posee más acepciones que acre cuyos significados remiten todos al latín más uno especializado aplicado en la medicina (3), pero los dos han mantenido las acepciones del latín, mientras que agrio amplió metafóricamente su uso al campo de la siderurgia (6) y la pintura (7).

Lo notable es que tanto la forma culta como la popular poseen la $1^{\mathrm{a}}$ documentación prácticamente simultánea (ss. XV-XVI) y la que las precede es agro ( $\left(1^{\text {a }}\right.$ dat. 1250$)$ lo que nos sugiere el siguiente desarrollo: acre $>$ agro (1250) $>$ por infl. de agriar $>$ agrio (s. XV) y acre (s. XVI).

\footnotetext{
${ }^{3}$ Siempre en base de: www.buscon.rae.es
} 


\section{cálido / caldo}

En el diccionario de Corominas (DCECH I / 764): cálido 'caluroso' aparece sv. caldo (DCECH I/759) del ant. adj. caldo 'caliente' y éste del lat. calìdus íd. Caldo como sustantivo está documentado por $1^{\mathrm{a}}$ vez hacia 1400 y como adj. en 1050 y 1155. Su uso como adjetivo desapareció pronto reemplazado por $\mathrm{ca}$ liente, sobrevivió como 'líquido que resulta de cocer en agua la carne y otras viandas' cuyo antecedente fue en latino 'vino caliente', más tarde se introdujo cálido como cultismo (hacia 1520 y 1560).

El estudio del corpus histórico nos muestra que, efectivamente, 1155 es la $1^{\mathrm{a}}$ datación de caldo 'cálido':

iure et leve ferro caldo ad ecclesia; et leve tres passares per foro de illa villa de Abiliés (Fuero de Avilés 1155);

aunque ya desde 1250 aparece como 'tipo de sopa':

E después que fuere cocho, cólenlo e échenles d'aquel caldo por las narices (Toledo 1250);

Cozina caldo. ius. Iuris (Nebrija 1495);

cálido 'caluroso' aparece en 1155:

iure el qui demanda sob' el morto, et leve ferro cálido ad ecclesia (Fuero de Avilés 1155);

para volver luego en los siglos siguientes:

por el viento que traían hasta allí ser Levante y por eso cálido (Diario del primer viaje de Colón 1492-93);

la bondad del celebro consiste en cálido y seco (Casas 1527);

y en forma gráfica calido en 1044:

quod abeo in Monte calido sive in Uranave (Cartulario de San Pedro de Arlanza 1044).

Los datos contradicen a Corominas según el cual la forma cálido se introdujo como cultismo hacia principios del siglo XVI $(1520,1560)$ : ésta fue documentada en español mucho antes: en 1155. De la misma manera, el vocablo caldo en acepción de 'líquido' se lo puede antedatar de 1400 a 1250.

La palabra latina calidus gozó de una polisemia significante:

1. calorem habens

2. translate calidus est praeceps, audaz, promptus, feroz, item sensu morali

3. calidum consilium (quod subito venit in mentem), calida mano (furtorum rea), caldos pedes (veloces) (Lexicon II / 33);

lo que corroboran Lewis \& Short traduciéndolo a 'warm, hot' y mencionando su aplicación figurativa: 'fiery, rash, pager, spirited, fuerce, impassioned, vehement, inconsiderate, hasty, rush' aplicándolo tanto a los animales (equus animis) como a consejo (consilium calidum 'quick, ready device'). En su diccionario aparece la mencionada por Corominas acepción de calidum (caldum) 'a hot drink (a mixture of wine and boiling hot water)'.

La voz caldus (Lexicon II / 30) aparece como adjetivo de calidus y sinónimo de calidus: 
1. adject. a calidus

2. omnio quod calidus, caldo

3. caldum et calidum.

Segura (2006: 89) traduce calidus por: 'cálido, caliente \| ardiente, fogoso, arrebatado, apasionado \|temerario, aventurado \|repentino, reciente, inmediatio'. Raimundo (2003: 132): 'cálido, caliente, precipitado, atrevido, veloz, ligero', además cita a Plauto: libere calidum 'beber algo caliente'. Du Cange (1884 II: 156) agrega el color del caballo: 'qui frontem albam, calidi (appellantur)'.

Actualmente, según la RAE, la repartición de significados entre cálido / caldo es la siguiente:

\section{caldo}

1. m. Líquido que resulta de cocer o aderezar algunos alimentos.

2. m. Jugo vegetal, especialmente el vino, extraído de los frutos y destinado a la alimentación. La Rioja es famosa por sus caldos.

3. m. En siderurgia, hierro u otro metal en estado líquido dispuesto para el molde.

cálido ${ }^{\mathbf{1}}$, da.

1. adj. Que da calor, o porque está caliente, o porque excita ardor en el organismo animal.

2. adj. caluroso (que siente calor o lo causa).

3. adj. Pint. Dicho del colorido: En que predominan los matices dorados o rojizos.

Ambas voces reflejan con bastante fidelidad el espectro semántico de la voz latina, solo que cálido extendió su significado en el campo léxico de la pintura (3) y caldo levemente cambió su significado de 'bebida caliente' a 'sopa, jugo' y, con el desarrollo de la técnica adquirió la acepción 'metal líquido' (3).

\section{foco / fuego}

Según Corominas (DCECH II/968) fuego proviene de lat. focus 'hogar', hoguera', 'brasero', su 1 a doc. remonta hacia los orígenes del idioma (fogo 1155) y en la baja época se empleó FOCUS 'fuego' (IGNIS) por lo menos en el s. IV, de lo que algo se conserva en la acepción 'hogar, vecino de una localidad' que tiene casa y hogar' ya en 1528 . Hacia 1500 cuando se impone la $h$-aspirada (prov. de $f$-) algunos prefirieron la forma aspirada huego (ej. Nebrija).

En cuanto al foco, remite a fuego, cita a Covarrubias (1610) 'fuego, casa....' y lo considera cultismo: "ant. foco (1708) propiamente 'hogar' duplicado culto de fuego" (DCECH II/ 923).

No es exactamente lo que resulta del estudio del corpus histórico:

que aqueste foco engendra que es el alma (Gómez de Zamora 1452).

La voz foco no aparece en el diccionario de Covarrubias y la variante huego queda documentada ya en el 1400: 
dentro todo hueco en cuya concaujdad se hazia huego (Biblia romanceada h. 1400);

la variante fuego en el s. XII:

Si mugier alguna matare su marido, muera por ello en muerte de fuego (Fuero de Soria 1196);

y fogo en 1155 :

De kasa (o) homo morar' é fogo fezer', dará I sólido de fornage (Fuero de Avilés 1155).

Así vemos que la forma foco, equivalente culto de fuego, aparece mucho antes de 1708 (según Corominas) porque ya en 1452, igual que huego un siglo antes (1400 y no 1500).

Para examinar los cambios semánticos, fijémonos en los significados latinos:

La palabra latina focus (Lexicon III/111) tiene varias acepciones:

1. quo ignis servatur: sive sit stabili loco inaedibus;

2. dicitur de privatis domibus;

3. item de vase ferreo, aeneo.

En el diccionario de Short \& Lewis:

1. a fire - place, hearth

2. a fire-pan, coal-pan, brazier

más el sentido figurativo: 'house, family'.

Según Segura (2006: 299): 'hogar, hoguera, pira \|ara, altar, hogar (fig.), chimenea, casa, hogar doméstico, paterno, braserillo, fuego, llama', según Raimundo (2003: 383) 'hogar, fogón, chimenea, casa particular, ara, hoguera; olla para cocer la comida; braserillo para conservar el fuego sagrado; fuego, llama'. Los mismos significados aparecen en el Glossarium (1884 III: 533): 'foco, caminus, locus ubi ignis accenditur, familia, domus' más : 'ferrum calidum' y como término de medicina: 'pars corporis, cui causa morbi insidet'.

Todas ellas se ven reflejadas en los significados actuales, más, obviamente las extensiones técnicas, aparecidas con el desarrollo de la técnica. Y así, en el DRAE:

\section{foco}

1. m. Lámpara eléctrica de luz muy potente concentrada en una dirección.

2. m. Lugar real o imaginario en que está como reconcentrado algo con toda su fuerza y eficacia, y desde el cual se propaga o ejerce influencia. Foco de ilustración, de vicios.

3. m. Fís. Punto donde se reúnen los rayos luminosos o caloríficos reflejados por un espejo cóncavo o refractados por una lente.

4. m. Fís. Punto, aparato o reflector de donde parte un haz de rayos luminosos o caloríferos.

5. m. Geom. Punto fijo que se utiliza en la generación de las cónicas. La elipse y la hipérbola tienen dos focos, y la parábola uno solo.

\section{fuego}

1. m. Calor y luz producidos por la combustión. 
2. m. Materia encendida en brasa o llama; p. ej., el carbón, la leña, etc.

3. $\mathrm{m}$. incendio.

4. m. quemador. Una cocina de tres fuegos

5. m. Efecto de disparar las armas de fuego.

6. m. hogar (familia). Este lugar tiene 100 fuegos

7. m. Encendimiento de sangre con alguna picazón y señales exteriores; como ronchas, costras, etc.

8. m. Ardor que excitan algunas pasiones del ánimo; como el amor, la ira, etc.

9. m. Viveza o empeño de una acción o disputa.

10. m. Hoguera que se hacía en las atalayas de la costa o en otros lugares para advertir de un peligro u otro acontecimiento.

11. m. Med. cauterio.

12. m. Mil. Flanco de una fortaleza.

13. m. pl. fuegos artificiales (artificios de pólvora).

Si bien la forma popular fuego goza de más significados ('brasa, incendio, hogar, ardor, viveza') siendo todas ellas continuación de las acepciones del lat. focus posee también acepciones técnicas (4), médicas $(7,11)$ y militares (12). El cultismo foco en este caso tiene significados más concretos, aplicados principalmente en ciencias exactas (física, geometría) más el uso metafórico 'centro de influencia' (2).

\section{masticar / mascar}

En la obra de Corominas masticar se encuentra sv. mascar (DCECH III / 873) y éste (DCECH III / 868) del lat. masticare 'íd.', según el autor: $1^{a}$ doc. APal. (1490): "mandere por comer y mascar", también en Nebrija: "mascar: mando, manduco"; probablemente del uso general en la Edad Media como lo era en los ss. XVI y XVII. A principios del s. XVII aparece ya esporádicamente la variante culta masticar a favor de la forma mascar que ganó terreno y es de uso general. La síncopa masticare > mascar no debe interpretarse como muy temprana, más bien como regresión de mast-gar por la fuerza asimiladora de la $t$ sorda y apoyada.

Según nuestra pesquisa en Covarrubias solo: mascar (2003: 792) 'término vulgar, vale comer dando dentelladas y desmenuzando entre los dientes la vianda con alguna fuerça'.

La forma masticar aparece recién en el s. XVIII (queda como cita del italiano en el Suplemento de Covarrubias del a. 1611 pero no como vocablo español):

y lo han de masticar rabiando (Feijoo 1730);

y la forma mascar ya en el s. XIII:

ell uso del comer perdudo. \& las quexadas enflaquecidas que no podien mascar (Alfonso X 1270);

Et el començo las a mascar (Alfonso X 1275). 
Otra vez aparece la discordancia en cuanto a la primera aparición: no tanto en el caso de masticar (Corominas: princ. del s. XVII, CORDE: 1730) como en el de mascar (Corominas: 1490, CORDE: 1270, 1275).

Masticare (Lexicon IV / 61) 'proprie est dentibus comminuo', no aparece en el diccionario de Lewis \& Short y en Glossarium (1884 V: 300): 'mandere, dentibus conficere' junto con 'perpendere, meditari'. Las demás fuentes coinciden en su significado: (Segura 2006: 449; Raimundo 2003: 559): 'masticar, mascar'.

Actualmente:

\section{mascar}

1. Partir y triturar algo con la dentadura.

2. coloq. Triturar la comida con la dentadura torpemente.

3. coloq. Dicho de un hecho importante: Considerarse como inminente. Se mascaba la tragedia, la revolución.

4. Mar. Dicho de un cabo: rozarse (raerse).

\section{masticar}

1. tr. Triturar la comida con los dientes u otros órganos bucales análogos.

2. tr. coloq. rumiar (considerar con reflexión y madurez).

Por lo que concierne el desarrollo semántico: la forma culta masticar mantuvo el uso más concreto, proveniente directamente de latín clásico más el figurativo presente en el latín medieval, mientras que la forma popular mascar adquirió los usos metafórico (3) y técnico (4).

\section{sólido / sueldo}

Es el caso donde un doblete está constituido por palabras pertenecientes a dos distintas clases gramaticales: un adjetivo y un sustantivo. Como veremos, tanto la pertenencia a ellas como los significados se dieron ya en el latín.

Según Corominas (DCECH IV / 1954 / 269) sueldo se origina del lat. tardío solidus 'cierta moneda de oro', 'ducado' que es propiamente el adj. clásico solidus 'sólido' sustantivado. $1^{\text {a }}$ doc. soldo es del año 1062-63, sueldo - del 1129. Sueldo ya en los textos medievales significa 'especie de moneda': antiguamente la paga que se daba a los soldados mercenarios fue por algún tiempo igual a un sueldo, y así el vocablo se hizo sinónimo de 'paga del mercenario' en (Palencia 1490) o Nebrija (1495). En cuanto a sólido (v. sueldo DCECH IV / 1954 / 269), son cultismos los siguientes: sólido $(1490,1633)$ del adj. solidus íd.

Tras el examen del corpus histórico resulta que la forma soldo 'especie de moneda' fue documentada ya en el s. XI:

et alia parte de dompna oro de palaçuelo comperauimus in soldo et medio (Compra... 1065) y según nuestros datos no aparece ni en Nebrija, ni en Covarrubias.

Sueldo fue documentado en el s. XII:

et prenda pora si peños por I sueldo (Fueros de Medinaceli 1129); 
Nebrija (1481): Stipendium est quod uulgo sueldo, (1495) Ganar sueldo. stipendium facio';

y después en Covarrubias (1611): 'en la guerra es el estipendio que se da al soldado'.

La forma sólido 'moneda' parece aparecer en los documentos escritos mucho antes que 1490:

De kasa (o) homo morar' é fogo fezer', dará I sólido de fornage (Fuero de Avilés 1155);

por precio de xixanta sólido jaqueto, los quales de vós oviemos e recebimos (Anónimo, Carta de venta 1349 [Documentos del Archivo Histórico Nacional (1200-1492)];

III sólidos son enna conta de los XLIIII moravedís e I sólido e vendemos todo esto e quanto eredamos enna pesquera (Anónimo, Dos cartas de venta 1208-1211 [Documentos del Archivo Histórico Nacional 1200-1492]);

dentro non ay miembros interiores, mas todo sólido con alguna poca de vacuidat en que se forma la boz (Villena 1427-1428) 'estable, lleno' - primera acepción como 'firme'.

La forma sólido no aparece en Nebrija pero sí en Covarrubias (2003: 943) en acepción de 'firme'.

Otra vez, habría que cambiar las fechas de la primera documentación, esta vez en el caso de sólido de 1490 a 1155.

Fijémonos en los posibles significados latinos:

En en Lexicon (V/ 549-550): 'proprie est plenus, integer, verus, nihil habens inanitatis, nulle parte laxatus et cavus, neque ex dissimilibus compositus, sed totus sin generis apud Mathemáticas: solidi numeri - planis oppositi et fractis, integer, totus, perfectus, verus, constans, stabilis';

según Lewis \& Short:

1. firm, dense, compact, not hollow, solid (terra solida, corpus, materia);

2. whole, complete, entire (integer, totus);

3. in partic. (...) in the time of the emperors a gols coin.

4. sound, solid, substantial, genuine, true, real.

Segura (2006: 717) remite a 'sólido, macizo, compacto, consistente, denso, firme, seguro', y traduce solidus [sc. nummus] por 'sueldo', propiamente 'moneda sólida, consolidada', moneda de oro, aunque admite que no fue un término usado por autores clásicos. Raimundo (2003: 866) soldus - forma sincopada de solidus 'sólido, macizo, entero', soldus, i - 'pieza de moneda' en Martialis. 'Prudens, sapiens' son las acepciones del Glossarium (1884 VII: 518).

Todas ellas se ven reflejadas en los usos actuales, y así según la RAE:

\section{sólido}

1. adj. Firme, macizo, denso y fuerte.

2. adj. Dicho de un cuerpo: Que, debido a la gran cohesión de sus moléculas, mantiene forma y volumen constantes.

3. adj. Asentado, establecido con razones fundamentales y verdaderas. 
4. m. Moneda de oro de los antiguos romanos, que comúnmente valía 25 denarios de oro.

5. m. Geom. cuerpo (objeto material de tres dimensiones).

\section{sueldo}

1. m. Remuneración regular asignada por el desempeño de un cargo o servicio profesional.

2. m. Moneda antigua, de distinto valor según los tiempos y países, igual a la vigésima parte de la libra respectiva.

3. m. sólido (antigua moneda romana).

El significado de sólido tras haber pasado por la acepción 'moneda' ha sido heredado directamente del latín, mientras que el de sueldo al transformarse por metáfora (ya en latín) en 'antigua moneda romana' pasó a denominar cierto tipo de 'estipendio', de ahí su significado actual de 'remuneración'.

\section{Conclusiones}

Más allá de las posibles antedataciones respecto al diccionario de Corominas, efecto que suele producirse con bastante frecuencia al trabajar con el material histórico, del presente estudio, por más breve que sea, desprenden al menos dos conclusiones principales.

No siempre el vocablo culto aparece cronológicamente tras el popular. Si bien la aparición de las formas como: acre, foco,masticar es relativamente tardía (ss. XV-XVII) y coincide con los periodos áureos de influjos latinizantes en la lengua española, el caso de cálido y sólido (los dos en 1155) por poco coinciden con la documentación de las formas populares. Ello quiere decir que algunos debieron de haber sido tomados en préstamo desde la época más temprana por lo que no se los puede considerar "voces literarias de introducción tardía en el idioma" como los definió el maestro Pidal. Efectivamente, basta fijarse en los llamados "periodos cultos" o sea periodos de la entrada de latinismos en el idioma español propuestos por Benítez Carlos (1960) o en el trabajo de Clavería Nadal (1991: 28-31) donde la autora presenta el resumen de las clasificaciones de los periodos cultos de Dámaso Alonso, Américo Castro, A. Yakov Malkiel o J.J. Bustos para darse cuenta de que éstos abarcan prácticamente toda la historia del español.

Pero lo que parece aún más interesante es la cuestión de la semántica de los dobletes. Todos los significados, menos los técnicos, aparecen en latín. Los casos de agrio, caldo, sólido sugieren que a veces la elección de significado se da en el español medieval aunque es solo una suposición y nos damos cuenta de que se debería hacer un estudio pormenorizado en un material más amplio. Además, al contrario de lo que se suele leer constantemente sobre el desarrollo semántico y la repartición entre el sentido más concreto y material de las voces populares y el más abstracto o rebuscado de las eruditas, notamos claramente 
que la situación real es sumamente distinta. Entre las cinco parejas que hemos estudiado, hay un caso de sinonimia (mascar / masticar), un caso de divergencia semántica pero iniciada ya en el mismo latín (sólido / sueldo). Es cierto que las formas populares suelen tener más acepciones (al menos cuantitativamente porque muchas de ellas son bastante parecidas) y si bien la forma foco tiene uso bastante restringido (poesía, técnica) de ninguna manera podemos aceptar la repartición tradicional entre el significado concreto adscrito a la voz popular y el abstracto al cultismo. Es al revés: el ejemplo de fuego, caldo o mascar comprueba que muchas de las acepciones técnicas, militares o medicinales son propias de voces populares oponiéndose, al menos parcialmente (v. foco) a la teoría de Traugott y Dasher (2005) según los cuales los préstamos suelen pertenecer a ámbitos de la ciencia y de la técnica, y su estilo y valor semántico quedan más restringidos. Tal vez la supremacía de los desarrollos semánticos en el caso de las voces populares se podría explicar por el simple hecho de que los cultismos son préstamos y los préstamos al entrar en el idioma receptor suelen reducir su cantidad de usos (v. Mańczak 1985). La creación de los dobletes podría ser explicada por la muy tentadora teoría de Anderson (1992) según la cual es la polisemia del étimo la que puede provocar los posibles cambios fonológicos: "one of these non-phonetic inducements to change may relate to the underlying polysemous characteristics of a word in which diverging semantic properties invite phonetic modifications" (Anderson 1992: 169) y el mecanismo de la repartición de formas y significados lo presenta la propuesta de Wright (1976) sobre la tendencia de las lenguas a evitar ambigüedades.

Nos damos cuenta de que solo es una muestra y que tal vez el estudio más complejo tanto cuantitativa como cualitativamente, nos podría revelar más datos sobre la verdadera naturaleza e historia de los dobletes en español. Pero aun siendo un trabajo de un tamaño reducido, es una muestra clara de que muchas veces las definiciones y teorías que barajamos y aplicamos en los trabajos históricos, no tienen su equivalencia en la realidad histórica del idioma.

\section{Datos bibliográficos}

Alfonso X. 1270. Estoria de Espanna que fizo el muy noble rey don Alfonso.

Alfonso X. 1275. General Estoria. Segunda parte.

Alvar M., Mariner Bigorra S. 1967. Latinismos y helenismos. - Alvar M. et al. (eds.) Enciclopedia lingüística hispánica II. Madrid.

Anderson J.M. 1992. Doublets, cultismos and their relation in Castillian Spanish. - Orbis 35: 166-170.

Benítez C.R. 1960. Sobre los períodos cultos. - Archivum 10: 398-404.

Biblia romanceada h. 1400.

Burgos de V. 1494. Traducción de El Libro de Propietatibus Rerum de Bartolomé Anglicus. Salamanca.

Cange du D. 1884. Glossarium mediae et infimae latinitatis. Niort.

Cartulario de San Pedro de Arlanza. 1044.

Casas de las B. 1527. Historia general de las Indias. Zaragoza.

Clavería Nadal G. 1991. El latinismo en español. Barcelona. 
Diario del primer viaje de Colón. 1492-1493.

Compra hecha por Bancio, abad de Fanlo, de varias fincas en Artao. 1065.

Corominas J., Pascual J. 1980. El diccionario etimológico castellano e hispánico. Madrid.

Covarrubias S. 2003. Tesoro de la lengua castellana o española. Barcelona. [1 $\left.{ }^{\mathrm{a}} \mathrm{ed} .1611\right]$.

Feijoo B. 1730. Teatro crítico universal. Madrid.

Forcellini A. 1858. Totius latinitatis Lexicon. Prati.

Fuero de Avilés. 1155.

Fuero de Soria. 1196.

Fueros de Medinaceli. 1129.

Gómez de Zamora A. 1452. Morales de Ovidio.

Gutiérrez B. 1989. Estudio histórico-semántico de los dobletes múltiples en español moderno. Granada.

Huarte J. 1575-1588. Examen de ingenios para las ciencias. Salamanca.

Kalinin A.B. 1971. Leksika russkogo jazyka. Moskva.

Korolenko I. 1969. Slovar etimologičeskij dubletov ispanskogo jazyka. Leningrad.

Lapesa R. 1980. Historia de la lengua española. Madrid.

Mańczak W. 1985. Semantic developments of borrowings. - Fisiak J. (ed.) Historical semantics, historical word-formation. Berlin: 367-375.

Nebrija de A. 1481. Introductiones latinae. Salamanca.

Nebrija de A. 1495. Vocabulario español-latino. Salamanca.

Palencia A. 1490. Universal Vocabulario. Sevilla.

Penny R. 2001. Gramática histórica del español. Barcelona.

Pidal M. 1992. Manual de gramática histórica española. Madrid.

Raimundo de M. 2003. Nuevo diccionario latino-español etimológico. Madrid. [1 $\left.{ }^{\mathrm{a}} \mathrm{ed} .1897\right]$.

Sălişteanu-Cristea O. 2000. Prestito latino - elemento ereditario nel léxico Della lengua italiana (doppioni e varianti). Praga.

Saussure F. 2007. Kurs językoznawstwa ogólnego. Warszawa.

Thesaurus linguae latinae. 1990. Lipsiae.

Segura Munguía S. 2006. Nuevo diccionario etimológico latín-español y de las voces derivadas. Bilbao.

Šanskij N.M. 1964. Leksikologija sovremennogo russkogo jazyka. Moskva.

Toledo de A. 1250. Moamín. Libro de los animales que cazan.

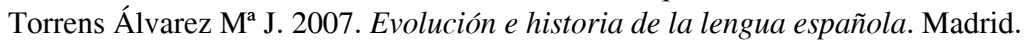

Traugott E.C., Dasher R.B. 2005. On regularity in semantic change. Cambridge.

Valera de D. 1487-1488. Crónica de los Reyes Católicos. Salamanca.

Villena E. 1427-1428. Traducción y glosas de la Eneida. Libros I-III.

Wright R. 1976. Semicultismo. - Archivum Linguisticum VII: 13-28.

\section{Enlaces de Internet}

Lewis C.T., Short C. A latin dictionary. <http://www.perseus.tufts.edu> [mayo 2008].

Diccionario de la Real Lengua Española. [22 $2^{\mathrm{a}}$ ed.] <http://www. buscon.rae.es> [abril 2008].

REAL ACADEMIA ESPAÑOLA: Banco de datos (CORDE) [en línea]. Corpus diacrónico del español. http://www.rae.es [abril 2008]. 
Studia Linguistica vol. 126/2009

Dobletes etimológicos en español - su origen y evolución semántica... 